Article

\title{
Integrating Insect Life History and Food Plant Phenology: Flexible Maternal Choice Is Adaptive
}

\author{
Minghui Fei ${ }^{1}$, Jeffrey A. Harvey ${ }^{1,2}$, Berhane T. Weldegergis ${ }^{3}$, Tzeyi Huang ${ }^{3}$, \\ Kimmy Reijngoudt ${ }^{3}$, Louise M. Vet ${ }^{1,3}$ and Rieta Gols ${ }^{3, *}$ \\ 1 Department of Terrestrial Ecology, Netherlands Institute of Ecology, Droevendaalsesteeg 10, \\ 6708 PB Wageningen, The Netherlands; m.fei@nioo.knaw.nl (M.F.); j.harvey@nioo.knaw.nl (J.A.H.); \\ 1.vet@nioo.knaw.nl (L.M.V.) \\ 2 Section Animal Ecology, Department of Ecological Sciences, VU University Amsterdam, \\ De Boelelaan 1085, 1081 HV Amsterdam, The Netherlands \\ 3 Laboratory of Entomology, Wageningen University, Droevendaalsesteeg 1, \\ 6708 PB Wageningen, The Netherlands; weldegergis@gmail.com (B.T.W.); tzeyipastry@gmail.com (T.H.); \\ kimmy.reijngoudt@wur.nl (K.R.) \\ * Correspondence: rieta.gols@wur.nl; Tel.: +31-317-483400
}

Academic Editor: Massimo Maffei

Received: 5 July 2016; Accepted: 26 July 2016; Published: 3 August 2016

\begin{abstract}
Experience of insect herbivores and their natural enemies in the natal habitat is considered to affect their likelihood of accepting a similar habitat or plant/host during dispersal. Growing phenology of food plants and the number of generations in the insects further determines lability of insect behavioural responses at eclosion. We studied the effect of rearing history on oviposition preference in a multivoltine herbivore (Pieris brassicae), and foraging behaviour in the endoparasitoid wasp (Cotesia glomerata) a specialist enemy of $P$. brassicae. Different generations of the insects are obligatorily associated with different plants in the Brassicaceae, e.g., Brassica rapa, Brassica nigra and Sinapis arvensis, exhibiting different seasonal phenologies in The Netherlands. Food plant preference of adults was examined when the insects had been reared on each of the three plant species for one generation. Rearing history only marginally affected oviposition preference of P. brassicae butterflies, but they never preferred the plant on which they had been reared. C. glomerata had a clear preference for host-infested B. rapa plants, irrespective of rearing history. Higher levels of the glucosinolate breakdown product 3-butenyl isothiocyanate in the headspace of $B$. rapa plants could explain enhanced attractiveness. Our results reveal the potential importance of flexible plant choice for female multivoltine insects in nature.
\end{abstract}

Keywords: endoparasitoid; foraging; glucosinolate; herbivore; herbivore induced plant volatile (HIPV); multivoltine; oviposition; rearing history; plant volatiles

\section{Introduction}

Herbivorous insects have to locate their host food plants often embedded in patches that may be species-rich and structurally and chemically complex [1,2]. Their co-evolved natural enemies, such as parasitoids and predators, are similarly challenged when they are searching for hosts or prey [1,2]. Location of these resources during foraging is often characterized by a gradual narrowing down of the area in which these resources can be found, and is described as a reliability-detectability problem [3]. For example, insect herbivores first have to find the proper habitat and then locate a suitable food plant within this habitat; their parasitoids must also overcome these same challenges to locate hosts that are often small and feeding in concealed locations on the food plant. Once potential food plants and/or hosts have been located, these can be accepted as oviposition sites or rejected, 
which is largely determined by differences in the suitability and quality of the resources for their development [4,5]. The first steps, i.e., habitat and host location, of this sequential process eventually leading to successful insect development primarily rely on visual and olfactory cues utilized by the insects [6-8]. In particular, volatiles that are released by plants in response to herbivore feeding (so-called herbivore induced plant volatiles (HIPVs)) have been extensively studied in relation to parasitoid foraging behaviour over the past 25 years [7,9-13].

The vast majority of insect herbivores are specialists that feed on only a few related plant species in nature $[14,15]$. Therefore, an herbivore and its specialist parasitoids are expected to rely on specific cues that are related to their food plants or hosts $[7,16,17]$ such as phylogenetically conserved secondary (defensive) metabolites [18]. For example, larvae of the cabbage butterflies Pieris brassicae and P. rapae, primarily feed on plant species in the family Brassicaceae that produce inducible glycoside compounds called glucosinolates $[19,20]$. Gravid female butterflies of these two species use these glucosinolates to recognize suitable food plants for their offspring by using their tarsi to "scratch" plant tissues prior to oviposition $[17,21]$.

Once they are in the appropriate habitat containing suitable plants or hosts, learning and subsequent experience may further influence the foraging behaviour of insect herbivores and their natural enemies when they are searching for resources. However, the strength of this effect often depends on the developmental stage at which the experience occurs. For example, oviposition experience of adult female parasitoids in the presence of characteristic volatile blends often enhances the parasitoid's response to these volatiles when these are offered in the absence of hosts [22]. This behavioural adaptation is referred to as associative learning and has been observed in both insect herbivores and their natural enemies [23]. Natal experience, which is obtained during larval feeding and growth, may also affect habitat preferences later in life during the adult stage. Known as the Hopkins's host selection principle (HHSP), it is, however, controversial as it implies that some form of imprinting is maintained during metamorphosis affecting later developmental stages [24] and also because evidence supporting the principle is thus far scarce [25]. Another major problem with the HHSP is that it does not take into account constraints imposed by temporal changes in diet that may be predicated by life history characteristics of the consumer and its resource. For insects that must switch plant diets from one generation to another (e.g., where the progeny exploit a different species of plant from their parents), it is clear that larval imprinting on a plant may be maladaptive if it hinders the ability of the insects to find and locate new resources that are chemically different from those on which they developed. Thus far, however, most studies tacitly assume that specialist herbivores exploit the same food plant species over many generations, making natal imprinting adaptive.

Some studies have shown that pre-adult experience can affect later foraging behaviour in insects for oviposition sites, at least if these sites are the same or at least very similar to those on which the offspring developed [26,27]. Furthermore, when natal experience influences later habitat choice, it increases the acceptance of the natal habitat type [28]. Preference for the natal habitat type could be beneficial for insects, because natal experience can influence plastic traits, such as the response to cues used during foraging, which make them better adapted to exploit the same resources in similar habitats [29]. Such preference is adaptive because it reduces the costs associated with exploring multiple habitats and in assessing the suitability of these habitats [27]. However, the strength of adaptation also depends on the degree to which the environment changes across space and time in relation to the generation time of the insects.

Many species of herbivorous insects are multivoltine and thus have two or more generations per year [30]. Moreover, some of these herbivores are known to feed on short-lived annual plants that are present in the field for only two or three months during the growing season [31]. Under these conditions, successive generations of herbivores that rely on short-lived annuals for food are obligated to leave the natal plant patch to locate and oviposit on a different plant species that may be different from the plant on which they developed and which grows a considerable distance (kilometers) away. 
Specialist multivoltine parasitoids of these herbivores are faced with the same constraints related to habitat and host location and thus must track them from one habitat patch to another.

In this study, we investigate the effect of rearing history on oviposition preference for different related host plant species in a multivoltine herbivore Pieris brassicae L. (Lepidoptera: Pieridae) and host plant preference behaviour in its endoparasitoid Cotesia glomerata L. (Hymenoptera: Braconidae). Caterpillars of $P$. brassicae are specialized on brassicaceous plant species of which all native species over much of its range are short-lived annuals. In the Netherlands, the species has generally three generations per year depending on temperature. The three annual plants studied here, wild turnip, Brassica rapa L., charlock mustard, Sinapis arvensis L., and black mustard, Brassica nigra L., were grown in temporal sequence and are important wild food plants for successive generations of $P$. brassicae in The Netherlands [31]. These plant species tend to grow in dense stands, which is a prerequisite for survival of $P$. brassicae because females lay eggs in clusters that need several plants to sustain their larval development [32]. Cotesia glomerata is a specialized gregarious endoparasitoid, i.e., females lay several eggs in the host at a single oviposition event. It primarily attacks early caterpillar stages of P. brassicae and it has two to three generations in the Netherlands, also depending on temperature.

The main aim of this study is to determine whether rearing history (i.e., insects reared on the different food-plant species [B. rapa, S. arvensis, B. nigra]) in one generation affects maternal preference of $P$. brassicae and foraging behaviour of $C$. glomerata for the three different plants infested with $P$. brassicae caterpillars. We hypothesize that the rearing history of the two insects will not affect preference for food plant species (herbivore) or volatile-mediated foraging (parasitoid) of future generations because pre-adult conditioning on the natal plant may confer costs e.g., the insects remaining within the natal patch may only encounter plants that are dying and are thus nutritionally unsuitable.

\section{Results}

\subsection{Host-Plant Oviposition Preference of Pieris brassicae Butterflies}

There was a significant difference in oviposition preference when the $P$. brassicae butterflies were reared on B. oleracea $\left(\chi^{2_{2}}=7.94, p=0.02\right.$ Figure 1a), B. nigra $\left(\chi^{2_{2}}=7.09, p=0.03\right.$, Figure $\left.1 \mathrm{~b}\right)$ or B. rapa $\left(\chi^{2}=9.80, p=0.007\right.$, Figure $\left.1 \mathrm{c}\right)$, whereas this was not the case for butterflies that were reared on S. arvensis $\left(\chi^{2_{2}}=2.36, p=0.31\right.$, Figure $\left.1 \mathrm{~d}\right)$. When reared on $B$. oleracea, female $P$. brassicae butterflies preferred to lay eggs on $B$. rapa, though this preference was only statistically significant for the pair-wise B. rapa-S. arvensis comparison. When reared on B. nigra, P. brassicae marginally preferred to lay eggs on B. rapa (B. rapa vs. S. arvensis $(\alpha=0.0167): \chi^{2_{1}}=5.54, p=0.019$; B. rapa vs. B. nigra, $\chi^{2_{1}}=3.57, p=0.059$, Figure $1 b$ ). With a rearing history on $B$. rapa or $S$. arvensis, butterfly oviposition preference ranked from low to high $B$. rapa $<$ S. arvensis $<B$. nigra (Figure 1c,d). Statistically, preference was significant only for the B. rapa-B. nigra pair-wise comparison for butterflies reared on B. rapa.

\subsection{Host-Plant Landing Preference of the Parasitoid, Cotesia glomerata}

In total, 1270 wasps made a choice in the wind tunnel, which was $92 \%$ of the wasps that were initially released in the wind tunnel. Rearing history had no effect on volatile-mediated foraging behaviour (Figure 2; B. nigra vs. S. arvensis: $\chi^{2_{3}}=4.02, p=0.26$; B. rapa vs. S. arvensis: $\chi^{2_{3}}=2.11$, $p=0.55 ;$ B. nigra vs. B. rapa: $\chi^{2_{3}}=3.68, p=0.30$ based on generalized linear model (GLM) analyses. Overall, wasps clearly preferred host-infested B. rapa plants over $S$. arvensis $\left(t_{37}=7.0, p<0.001\right)$ and $B$. nigra plants $\left(t_{39}=6.2, p<0.001\right)$, though, in the latter case, this preference was less pronounced when the wasps had been reared on B. nigra (Figure 2c). They also preferred host-infested B. nigra over $S$. arvensis plants $\left(t_{38}=2.7, p=0.01\right)$, especially when they had been reared on $B$. nigra (Figure 2a). Furthermore, both plant architecture (GLM: $\chi^{2_{1}}=0.12, p=0.73$, Figure 3 ) and early exposure to HIPV had no effect on wasp landing preference (GLM: $\chi^{2_{1}}=1.66, p=0.20$, Figure 4). 
(a)

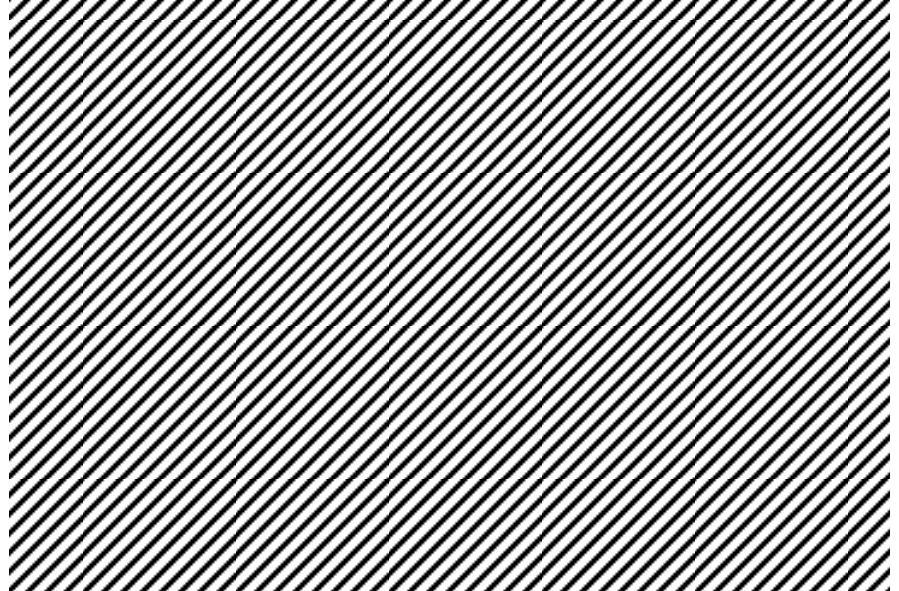

Figure 1. Oviposition preference of female Pieris brassicae that had been reared on: Brassica oleracea (a); Brassica nigra (b); Brassica rapa (c); and Sinapis arvensis (d) in a three-way choice assay with B. rapa (dashed bars), S. arvensis (white bars), and B. nigra (grey bars) plants. Bars represent the total preference number, and bars with the same letter are not significantly different from each other (pairwise $\chi^{2}$ test with a Bonferroni correction for multiple comparisons Type I errors). Samples sizes are given in brackets.

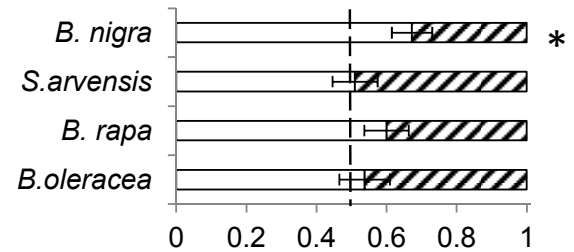

(a)

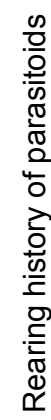

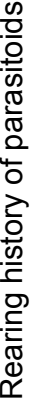

B. nigra

S.arvensis

B. rapa

B.oleracea

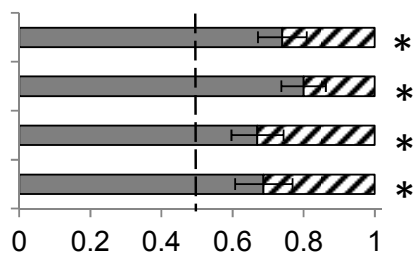

(b)

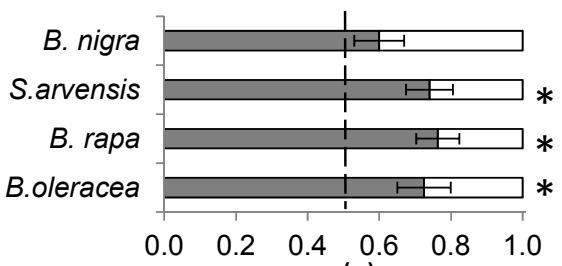

(c)

Proportional preference for each odour source

Figure 2. Landing preference of female Cotesia glomerata that had been reared on Brassica oleracea, Brassica rapa, Sinapis arvensis, or Brassica nigra, in a pair-wise choice assays with: (a) B. nigra (white bars) and S. arvensis (dashed bars); (b) B. rapa (grey bars) and S. arvensis; or (c) B. rapa and B. nigra when infested with Pierisrs brassicae caterpillars for $24 \mathrm{~h}$. Bars present the mean proportion ( \pm standard error of the mean or SE) of choice based on 10 replicate bioassays each tested with 10 responding wasps. An asterisk indicates a significant preference within a plant pair. 


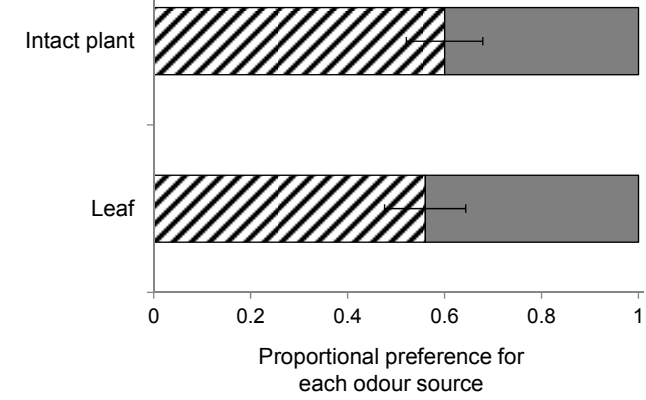

Figure 3. Landing preference of female Cotesia glomerata in a choice bioassay with intact plants (top bar) or leaves (bottom bar). Wasps had been reared on Brassica nigra and were given the choice between Brassica rapa (dashed bars) and B. nigra (grey bars) infested with 20 first instar Pieris brassicae for $24 \mathrm{~h}$. Bars present the mean proportion $( \pm \mathrm{SE})$ of choice based on 10 replicate bioassays each tested with 10 responding wasps.

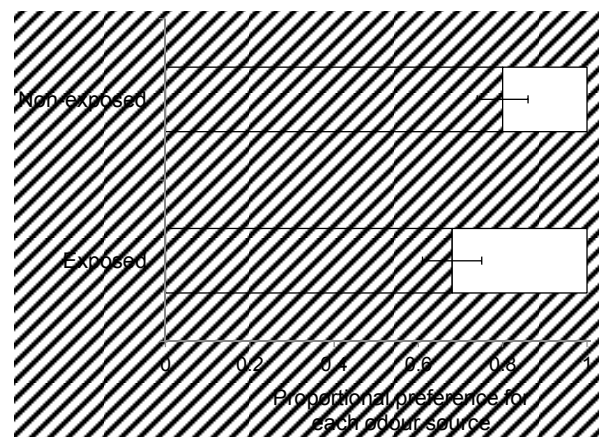

Figure 4. Landing preference of female Cotesia glomerata eclosing from cocoons produced by host caterpillars that had been removed from the plants before the parasitoid larvae egressed from the host (non-exposed group, top bar) and those eclosing from cocoons that were left on the plants on which the caterpillars had developed until adult eclosion (exposed group, bottom bar). Wasps had been reared on Sinapis arvensis and were given the choice between a Brassica rapa (dashed bars) and a S. arvensis plant (white bars) infested with 20 first instar Pieris brassicae for $24 \mathrm{~h}$. Bars present the mean proportion $( \pm \mathrm{SE})$ of choice based on 10 replicate bioassays each tested with 10 responding wasps.

There were significant differences in the amount of leaf tissues consumed by P. brassicae larvae among the three plant species $\left(\mathrm{F}_{2,54}=3.38, p=0.041\right)$ (Figure 5). The damage inflicted to $S$. arvensis plants was marginally, though not statistically, greater than the damage inflicted to B. rapa (Tukey test: $p=0.06$, Figure 5) and B. nigra (Tukey test: $p=0.08$, Figure 5). Damage levels were similar on $B$. rapa and B. nigra plants (Tukey test: $p=0.99$, Figure 5).

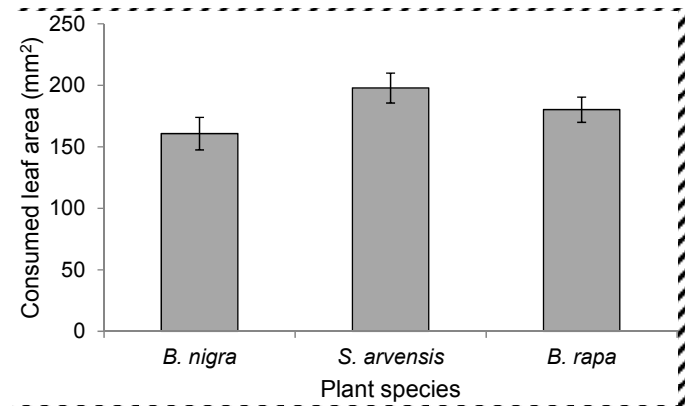

Figure 5. Leaf area consumed by 20 first instar Pieris brassicae feeding for 24 h on either Brassica rapa, Sinapis arvensis, or Brassica nigra plants. Bars present the means \pm SE $(n=19)$. 


\subsection{Headspace Analysis}

In the headspace of B. rapa, S. arvensis, and B. nigra that had been fed upon by P. brassicae larvae for $24 \mathrm{~h}, 33$ different compounds were detected, of which 29 were present in the HIPV blend of all three host plant species (Table 1).

Table 1. Volatile compounds emitted by Brassica rapa, Sinapis arvensis, and Brassica nigra plants damaged by 20 first instar Pieris brassicae caterpillars for $24 \mathrm{~h}$.

\begin{tabular}{|c|c|c|c|c|}
\hline \multirow{2}{*}{ ID $^{b}$} & Plant Species & B. rapa ${ }^{a}$ & S. arvensis & B. nigra \\
\hline & Compound & $(n=13)$ & $(n=10)$ & $(n=9)$ \\
\hline 1 & 2-Methylbutanenitrile ${ }^{* * *}$ & $91.8 \pm 24.4$ & $3.7 \pm 0.8$ & $3.8 \pm 0.4$ \\
\hline 2 & 3-Methyl-3-butenenitrile *** & $6.1 \pm 2.0$ & ND & ND \\
\hline 3 & (E)-2-Hexenal & $0.7 \pm 0.1$ & $0.6 \pm 0.2$ & $0.3 \pm 0.07^{7, !}$ \\
\hline 4 & (Z)-3-Hexen-1-ol *** & $20.3 \pm 3.0$ & $6.7 \pm 1.4$ & $7.5 \pm 2.0$ \\
\hline 5 & Allyl isothiocyanate $* * *$ & $0.2 \pm 0.1^{7}$ & $1.4 \pm 0.6^{7}$ & $135.2 \pm 22.6$ \\
\hline 6 & Butane, 1-isothiocyanato *** & $14.7 \pm 5.3$ & $0.5 \pm 0.2^{8}$ & $0.5 \pm 0.08^{8}$ \\
\hline 7 & (E)-4-Oxo-2-hexenal * & $16.5 \pm 2.7$ & $14.9 \pm 6.5^{8}$ & $5.6 \pm 2.4^{7}$ \\
\hline 8 & Sabinene & $0.9 \pm 0.1$ & $1.1 \pm 0.2^{9}$ & $1.0 \pm 0.1$ \\
\hline 9 & 3-Butenyl isothiocyanate $* * *$ & $20.1 \pm 5.1$ & $0.05 \pm 0.08^{2}$ & $0.7 \pm 0.1$ \\
\hline 10 & Myrcene & $3.5 \pm 0.3$ & $2.9 \pm 0.4$ & $3.0 \pm 0.3$ \\
\hline 11 & (Z)-3-Hexen-1-ol, acetate & $165.4 \pm 20.8$ & $49.7 \pm 9.4$ & $21.9 \pm 7.9$ \\
\hline 12 & Hexanoic acid, 2-ethyl-, methyl ester *** & $1.6 \pm 1.2$ & $3.6 \pm 2.7$ & $0.1 \pm 0.09^{6}$ \\
\hline 13 & $(E)-\mathrm{DMNT} *$ & $26.4 \pm 11.0$ & $4.3 \pm 1.2$ & $28.8 \pm 7.7$ \\
\hline 14 & Unknown & $0.4 \pm 0.02$ & $0.3 \pm 0.07^{8}$ & $0.4 \pm 0.04$ \\
\hline 15 & Menthol & $2.7 \pm 0.9$ & $2.0 \pm 0.3$ & $3.7 \pm 0.8$ \\
\hline 16 & Unknown & $0.5 \pm 0.1$ & $1.1 \pm 0.3$ & $0.8 \pm 0.3$ \\
\hline 17 & Unknown & $0.7 \pm 0.2$ & $1.6 \pm 0.6$ & $0.8 \pm 0.3$ \\
\hline 18 & Methyl salicylate *** & $2.6 \pm 0.7$ & $0.3 \pm 0.04$ & $0.7 \pm 0.2^{8}$ \\
\hline 19 & Presilphiperfol-7-ene ${ }^{* * *}$ & ND & ND & $0.4 \pm 0.1^{7}$ \\
\hline 20 & 7- $\beta$-H-Silphiperfol-5-ene $* * *$ & ND & ND & $0.5 \pm 0.2^{7}$ \\
\hline 21 & $\alpha$-Terpinyl acetate $*$ & $0.3 \pm 0.05$ & $0.4 \pm 0.06^{9}$ & $0.2 \pm 0.06^{7}$ \\
\hline 22 & Silphiperfol-6-ene ${ }^{* * *}$ & ND & ND & $0.2 \pm 0.1^{7}$ \\
\hline 23 & $\alpha$-Funebrene ${ }^{* *}$ & $0.1 \pm 0.05^{11}$ & $0.09 \pm 0.02^{8}$ & $0.6 \pm 0.1$ \\
\hline 24 & $\beta$-Caryophyllene ** & $2.2 \pm 1.4^{6}$ & $9.3 \pm 3.7$ & $0.02 \pm 0.05^{1}$ \\
\hline 25 & $(E)-\alpha$-Bergamotene & $0.09 \pm 0.06^{6}$ & $0.1 \pm 0.04^{7}$ & $0.2 \pm 0.08^{7}$ \\
\hline 26 & $\alpha$-Guaiene & $0.1 \pm 0.03$ & $0.1 \pm 0.03^{8}$ & $0.09 \pm 0.03^{8}$ \\
\hline 27 & (E)- $\beta$-Bergamotene & $0.2 \pm 0.2^{5}$ & $0.05 \pm 0.2^{1}$ & $0.2 \pm 0.1^{5}$ \\
\hline 28 & $\alpha$-Caryophyllene & $0.5 \pm 0.3^{5}$ & $1.1 \pm 0.6^{6}$ & $0.03 \pm 0.08^{1}$ \\
\hline 29 & $(E, E)-\alpha$-Farnesene ${ }^{* * *}$ & $22.8 \pm 10.6$ & $0.3 \pm 0.2^{4}$ & $0.9 \pm 0.3^{7}$ \\
\hline 30 & $\alpha$-Bulnesene & $0.1 \pm 0.04^{8}$ & $0.06 \pm 0.1^{2}$ & $0.04 \pm 0.1^{1}$ \\
\hline 31 & Methyl cis-dihydrojasmonate & $7.1 \pm 1.3$ & $9.5 \pm 1.3$ & $12.0 \pm 1.1$ \\
\hline 32 & Unknown * & $20.0 \pm 2.7$ & $30.0 \pm 6.7$ & $43.1 \pm 6.3$ \\
\hline 33 & Unknown * & $4.7 \pm 0.6$ & $6.8 \pm 1.3$ & $10.0 \pm 1.3$ \\
\hline & Total *** & $433.5 \pm 50.4$ & $152.4 \pm 25.9$ & $283.2 \pm 32.7$ \\
\hline
\end{tabular}

${ }^{a}$ Volatile emissions are given as a mean peak area $\pm \mathrm{SE} / \mathrm{g}$ fresh weight of foliage divided by $10^{5}$ with number of sample replicates $(n)$ between brackets; ${ }^{\mathrm{b}}$ ID corresponds with the number presented in loading plot (Figure 6b); ! Numbers in superscript following emission quantities represent the number of samples in which a given compound was detected. ND = not detected in any of the samples; * Compounds with asterisks indicate significant differences in emission quantities of volatiles among the three plant species (Kruskal-Wallis one-way ANOVA, ${ }^{*} p<0.05 ;{ }^{* *} p<0.01$; $\left.{ }^{* * *} p<0.001\right)$; (E)-DMNT: (E)-4,8-dimethylnona-1,3,7-triene.

Based on PCA analysis of the volatiles, samples from the three plant species clearly separated (Figure 6a). The first PC, explaining $28.94 \%$ of the variation, separated B. rapa from B. nigra, whereas the second PC, explaining an additional $24.76 \%$ of the variation, further separated $S$. arvensis from $B$. rapa and B. nigra plants (Figure 6a). This means that the volatile blends emitted by B. rapa and B. nigra were more dissimilar compared to the blend emitted by $S$. arvensis plants. There was a significant difference in the total amount of volatiles emitted by the three plant species $\left(\mathrm{F}_{2,29}=15.3, p<0.001\right)$. Brassica rapa 
and B. nigra emitted a larger volume of volatiles than S. arvensis (Tukey multiple comparison tests: B. rapa vs. S. arvensis and B. nigra vs. S. arvensis both $p<0.05$, B. rapa vs. B. nigra $p>0.05$ ). Compounds that were emitted in higher amounts by $B$. rapa were the two nitriles: 2-methylbutanenitrile (ID 1), and 3-methyl-3-butenenitrile (ID 2); the glucosinolate hydrolysis product: 3-butenyl isothiocyanate (ID 9); the two green leaf volatiles (Z)-3-hexen-1-ol (ID 4) and (Z)-3-hexen-1-ol-acetate (ID 11) and the sesquiterpene $(E, E)-\alpha$-farnesene (ID 29) (Figure $6 b$, Table 1). B. nigra plants were characterized by the relatively high emissions of the glucosinolate breakdown product allyl isothiocyanate (ID 5), and silphiperfolene isomers (ID 19, 20, 22), which were absent or only emitted in very small amount by the other two plant species (Figure $6 \mathrm{~b}$, Table 1 ). S. arvensis plants produced relatively more of the sesquiterpernes $\alpha$-and $\beta$-caryophyllene (ID 24 and 28) (Figure 6b, Table 1).

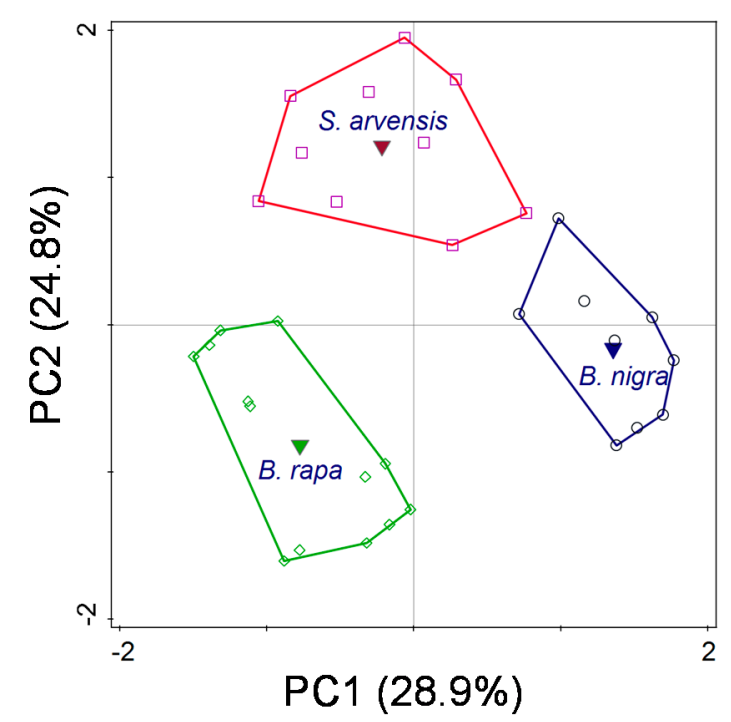

(a)

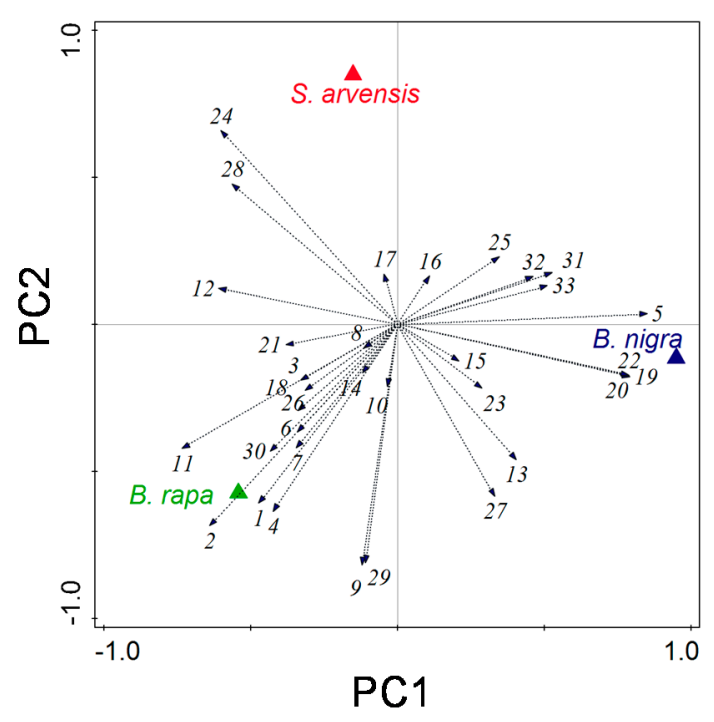

(b)

Figure 6. Principal component analysis (PCA) on the quantitative data of volatile compounds emitted by Brassica rapa $(n=13)$, Sinapis arvensis $(n=10)$, and Brassica nigra $(n=9)$ plants in response to Pieris brassicae feeding for $24 \mathrm{~h}$. The score plots of the samples (a) depict separation of the different plant species along the first and second PC with the explained variance between brackets. The corresponding loading plot of the variables (b) shows the contribution of each volatile compound to the first two PCs and the sample groups (here plant species). For the identity of compounds presented as numbers in the loading plot (b), please refer to Table 1.

\section{Discussion}

In this study, we show that rearing history only partially affected oviposition preference of P. brassicae butterflies and never resulted in a preference for the plant on which it had been feeding during larval development. It also had little or no effect on the foraging behaviour (i.e., plant preference) of its parasitoid, C. glomerata. Whereas P. brassicae butterflies reared on the different food plants did not exhibit any consistencies in oviposition preference behaviour, C. glomerata clearly preferred to alight on herbivore-damaged B. rapa plants. Preference of C. glomerata for B. rapa could not be explained by plant architecture, given that it is structurally similar, albeit slightly smaller, than the other two brassicaceous plant species studied here. Headspace analyses also revealed significant quantitative and qualitative differences among the HIPV blends emitted by the three plant species.

Natal experience has been reported to affect adult habitat selection by insects [27,33,34], but few studies have investigated this in lepidopteran species (butterflies and moths). Larval feeding experience with a feeding deterrent modified oviposition responses of subsequent adults in the moth species, Ephestia cautella and Plodia interpunctella [35] Trichoplusia ni [36], Spodoptera littoralis [37] 
and Lobesia botran [38]. To affect choices made during oviposition preference, cues obtained in the natal habitat must be memorized during larval feeding and carried through pupation to the adult stage. However, in holometabolous insects, the nervous system is profoundly reorganized during metamorphosis [39,40], which makes it unlikely that experience learned during the larval stage is easily retained in adult insects [25].

In nature, $P$. brassicae has up to three generations per year across much of its native range in Western and central Europe [31,41]. Furthermore, P. brassicae larvae require many food plants to support the successful development of a single brood, a requirement that limits the number of suitable plant species as oviposition sites in nature to about six or seven [32]. These plants, including the three species studied here, grow in large tightly assembled populations that enable the caterpillars to disperse from the natal plant to adjacent plants later during larval development by moving through the canopy [32,42]. Importantly, qualitatively and quantitatively suitable food plants are annuals or biennials with short growing seasons, and many of these plants also exhibit discrete periods of growth during the season. For example, B. rapa generally grows between March and May, S. arvensis between May and July, and B. nigra between June and August [31]. This means that different generations of $P$. brassicae must search for different host plants that generally grow at different locations, often a considerable distance away from the natal patch. Therefore, it is adaptive for P. brassicae that oviposition preference is not affected by larval rearing history; otherwise, the adults would risk wasting time searching for food plants that are no longer present (or which are no longer nutritionally suitable) in the natal habitat. Natal experience is only expected to affect plastic traits when it benefits animal fitness [29]. The fact $P$. brassicae is multivoltine and a specialist on short-lived, clustered brassicaceous plant species may explain why the effect of natal imprinting on adult oviposition preference is weak or non-existent. Though butterflies never preferred the plant on which they had been reared, the rank order of oviposition preference differed with natal experience; females preferred B. rapa plants for oviposition when reared on B. oleracea and B. nigra and preferred B. nigra when reared on B. rapa or S. arvensis.

Natal imprinting is not only found in lepidopteran species, but has also been observed in some species of Hymenoptera [28,43]. Several studies have shown that the response of adult female parasitoids to HIPV differs depending on the diet on which their host was feeding during larval parasitoid development inside of the host body [44,45]. For example, the ectoparasitoid Hyssopus pallid was more attracted to frass from its fruit-feeding host Cydia pomonella when the wasps had developed on hosts fed on apples compared to wasps reared on hosts fed on artificial diet [46]. The length of rearing history can also play a role in the wasp's future plant volatile preferences [47]. For instance, when Plutella xylostella that are parasitized by Diadegma semiclausum were fed on snow pea for three successive generations, female wasps showed a relatively higher preference to snow pea volatiles in the third than in the first generation [47]. In our study, the parasitoid was only reared on hosts and plants for a single generation, reflecting conditions found in nature, where different generations generally must find hosts on different plant species. Consequently, we found that natal experience had no effect on volatile-mediated foraging behaviour in C. glomerata. The adaptive potential of natal imprinting clearly depends on such factors as the reliability of being associated with the same plant species or the degree of chemical and structural similarity of different plant species that may be used in successive generations by the herbivore and its parasitoid. Natal experience is adaptive when the environment is predictable over several generations in an insect. For multivoltine parasitic wasps, where different generations also need to search for hosts on different plant species in different habitats, it is important that natal experience exerts little effect on their landing preference.

We also found that early exposure to HIPV at eclosion had no effect on wasp landing preference. By contrast, host plant stimuli have been reported to increase a parasitoid's attraction to the natal host plant [48]. For example, the attraction of the parasitoid wasp Trichogramma brassicae to tomato plants increased when the wasps were allowed to emerge from their hosts in the presence of these plants. Similarly, attraction of $C$. congregata to cherry volatiles increased when the parasitoid had physical 
contact with the host plant at eclosion. Therefore, the importance of conditioning at eclosion appears to be association-specific and even differs amongst closely related taxa (e.g., C. glomerata and C. congregata). This could be due to differences in life-history traits among the plants and insects. In the case of C. congregata, its herbivore hosts (e.g., the larvae of sphingid moths) may associate with the same food plants and/or habitats over successive generations, making conditioning adaptive. Certainly more plant host-parasitoid associations need to be studied to extrapolate potential relationships between the life-history of the plants and hosts and conditioning/innate responses in their parasitoids.

Female parasitoids clearly preferred B. rapa over the other two cruciferous species. Several factors could contribute to this preference. $B$. rapa grows early in the season and may therefore be one of the few plant species available in the Netherlands for P. brassicae when they emerge from winter diapause. Consequently $C$. glomerata may have evolved a strong sensitivity to (volatile) cues related to the first available food plant of its host. Alternatively, some of the volatiles emitted by B. rapa may trigger a stronger sensory response in the parasitoid than compounds in the blend of B. nigra and S. arvensis. Little is still known as to the identity of specific volatiles or volatile blends that are most attractive to parasitoids [45], although some compounds have been shown to play an important role in enhancing attractiveness of the blend $[49,50]$.

The analysis of the HIPV blends showed that there were significant quantitative and qualitative differences among the three plant species. The total amounts of volatiles from B. rapa and B. nigra were significantly larger than from S. arvensis. When HIPV blends induced by different treatments of the same plant species are compared, quantitative aspects of these blends may to a large extent determine parasitoid attraction $[49,51]$. However, when parasitoid attractiveness to HIPV blends emitted by different plant species is compared, qualitative rather than quantitative aspects may be more important [45]. It is known that blends produced by species in the Brassicaceae vary dramatically across different species [52,53].

All brassicaceous plant species produce glucosinolates [54], which function as defensive compounds against a range of attackers such as pathogens and insect herbivores [20,55]. Deterrent or toxic activity only emerges after tissue damage, e.g., by caterpillar feeding and concomitant release of the enzyme myrosinase, which is stored in specialized cells. This enzyme catalyses the conversion of glucosinolates into toxic hydrolysis products, of which many are volatile [55]. These volatile breakdown products have been shown to serve as reliable signals for the parasitoid C. rubecula to their host, $P$. rapae [56]. If breakdown products of glucosinolates play a role in host plant selection by $C$. glomerata, the high amounts of 3-butenyl isothiocyanate, which is the breakdown product of gluconapin, the dominant glucosinolate in B. rapa, may explain its enhanced attraction to this plant. However, this does not explain why B. rapa is more attractive than B. nigra which emits allyl isothiocyanate in even larger amounts than B. rapa emits 3-butenyl isothiocyanate (allyl isothiocyanate is a hydrolysis product of sinigrin, the dominant glucosinolate in B. nigra). Diaeretiella rapae, a parasitoid of the aphid Brevicoryene brassicae that is a specialist of brassicaceous plants, was shown to be more attracted to synthetic 3-butenyl isothiocyanate than to 4-pentenyl isothiocyanate [50], although it is also attracted to synthetic allyl isocyanate [57]. This suggests that isothiocyanates are differentially attractive to parasitoids. The low volatility of hydrolysis products of sinabin, the dominant glucosinolate in S. arvensis, may be responsible for the absence of these compounds in the headspace of S. arvensis explaining the reduced attractiveness of these plants to C. glomerata.

In summary, our study reveals that rearing history has little or no effect on oviposition preference of $P$. brassicae butterflies or landing preference of its major parasitoid C. glomerata. Oviposition preference of P. brassicae shifted between B. nigra and B. rapa, but the butterflies never displayed a clear preference for the plant species on which they had been reared. C. glomerata had a clear preference for host-infested B. rapa plants. For multivoltine insects, such as P. brassicae and C. glomerata that primarily rely on short-lived annuals for immature development, it is a challenge for different generations to locate suitable host plants, given that they are forced to leave the natal habitat to do so. Therefore, it is adaptive that these insects are labile in the cues that they use in host plant 
location behaviour and, thus, that it is not affected by natal imprinting. Furthermore, our study also shows that the herbivore and the parasitoid use different cues when searching for food or host plants. To better understand the mechanisms that underline these interactions, it is important to examine an array of ecophysiological constraints on the insects and the traits the insects exhibit to counter them. Clearly, the biology and phenology of the food plant(s) leave an indelible mark on their insects.

\section{Materials and Methods}

\subsection{Plants}

B. rapa, B. nigra and S. arvensis seeds were collected from natural growing populations in Gelderland, The Netherlands. Seeds were germinated and seedlings were subsequently transferred to 1.1-L pots filled with peat soil (Lentse potgrond no.4; lent, The Netherlands). Plants were grown in a greenhouse at the Netherlands Institute of Ecology (NIOO) under the following conditions: $21 \pm 2{ }^{\circ} \mathrm{C}$ (day) and $16 \pm 2{ }^{\circ} \mathrm{C}$ (night), $50 \%$ relative humidity, and a photoperiod of at least $16 \mathrm{~h}$. The plants were watered twice a week during the first 3 weeks of development. When the plants were 3 weeks old, they were fertilized once a week with Hoagland solution, which was applied to the soil. Watering and fertilization continued during the experiments.

As the insects have been reared on Brussels sprout plants, Brassica oleracea L. var. gemmifera cv. Cyrus for many $(>10)$ generations, this plant was used as a control. Brussels sprout plants were grown from seeds in peat soil in $1.1-\mathrm{L}$ plastic pots in a greenhouse $\left(50 \%-70 \%\right.$ relative humidity, $20-25{ }^{\circ} \mathrm{C}$, and a photoperiod of $16 \mathrm{~h}$ ) and were 4 to 5 weeks old when used in the experiments.

\subsection{Insects}

P. brassicae and C. glomerata were collected in experimental fields near Wageningen, The Netherlands. P. brassicae caterpillars were reared on Brussels sprout plants in a greenhouse at $50 \%-70 \%$ relative humidity, $20-25{ }^{\circ} \mathrm{C}$, and a photoperiod of $16 \mathrm{~h}$ at Wageningen University (WU). C. glomerata was reared on young P. brassicae caterpillars feeding on Brussels sprouts. Once the fully developed larvae of C. glomerata emerged from P. brassicae hosts and had spun cocoons, they were collected for further rearing or experimental purposes. Approximately five days after cocoon formation, adult wasps emerged at which point they were provided with $10 \%$ sugar solution.

\subsection{Preparation of Insects Used in Experiments}

\subsubsection{Herbivore}

P. brassicae were reared from egg-to-adult for one generation on one of the three host plant species: B. rapa, S. arvensis or B. nigra. We also determined oviposition preference of butterflies reared on B. oleracea on which they had been reared for many generations. Single four-week-old B. oleracea and three-week-old B. rapa, S. arvensis, or B. nigra plants were placed in the rearing cage with adult P. brassicae butterflies for $24 \mathrm{~h}$. Plants with egg clusters were transferred to a cage with additional plants of the same species as the one on which the eggs were laid. Eggs were allowed to develop into pupae on their respective food plants. Eclosing butterflies were provided with a (20\%) honey solution and were allowed to mate. Butterflies were $3-5$ days old when they were used in the choice bioassays.

\subsubsection{Parasitoid}

C. glomerata were reared for one generation on P. brassicae caterpillars feeding on one of the four host plant species: B. oleracea, B. rapa, S. arvensis or B. nigra. Caterpillars of P. brassicae were obtained and reared as described in the previous section until they reached the mid first instar stage. For parasitism, female wasps were collected from the general culture. First instar P. brassicae caterpillars were parasitized by presenting them individually to a female wasp. After parasitism by $C$. glomerata, caterpillars were introduced onto one of the four host plant species (B. oleracea, B. rapa, S. arvensis or 
B. nigra), which were maintained in separate cages until the larvae of the parasitoids emerged and formed cocoons. Parasitoid cocoons were collected in Petri dishes $(9.5 \mathrm{~cm})$ and were maintained in an incubator at $21 \pm 1{ }^{\circ} \mathrm{C}$ until adult eclosion at which point they were transferred into $30 \times 30 \times 30 \mathrm{~cm}$ (Bugdorm) plastic cages and provided with 10\% sugar, water, and honey. Female wasps used in the bioassays were $2-8$ days old.

\subsection{Host-Plant Oviposition Preference of Pieris brassicae Butterflies}

Oviposition preferences were assessed in three-choice experiments in six outdoor tents $(3 \times 4 \times 2 \mathrm{~m})$ placed on bare soil in an experimental field adjacent to WU. Plants from each species were prepared as described in the Plants section.

Single plants of each of the three plant species were randomly placed in a triangle, approximately $1.5 \mathrm{~m}$ apart, in the experimental tents. One female and one male butterfly were released in the middle of the tent. A bioassay was terminated and its choice recorded when a female butterfly had laid the first egg clutch, which was checked three times a day. Females were used only once. The bioassay was repeated at least 30 times with butterflies being reared on the same plant species. Bioassays were conducted from June to August 2013. New plants were used for each replicate and the positioning of the plant species in the tent was randomized.

\subsection{Host-Plant Landing Preference of the Parasitoid, Cotesia glomerata}

In a wind tunnel set-up (see below), we determined HIPV mediated landing preference of female C. glomerata parasitoids when reared for one generation from P. brassicae caterpillars developing on of the host plants, B. rapa, S. arvensis and B. nigra, respectively. In addition, we used wasps that had developed in P. brassicae feeding on B. oleracea, the food plant on which the insects had been reared for $>10$ generations. In the wind tunnel, plant pairs, i.e., all three combinations of host-infested B. rapa, $S$. arvensis and $B$. nigra plants were offered to parasitoids reared on the four different food plants. Individual plants were infested with 20 first instar P. brassicae or 10 second instar P. brassicae caterpillars, depending on caterpillar availability, and incubated in a greenhouse for $24 \mathrm{~h}$ at $50 \%-70 \%$ relative humidity and $20-25{ }^{\circ} \mathrm{C}$ with a photoperiod L:D of $16: 8 \mathrm{~h}$. Plant combinations used in single choice bioassays were always infested with the same number of caterpillars of the same instar.

To determine whether differences in the amount of feeding damage affected landing preference, we determined for each of the three plant species ( $n=19$ per plant species) the amount of leaf tissue consumed from plants infested by 20 first-instar P. brassicae larvae for $24 \mathrm{~h}$. Damaged areas were calculated using millimeter paper on transparent plastic sheets.

The plant species differ in their architecture, which could affect landing preference of the wasps. For instance, S. arvensis and B. nigra grow taller than B. rapa, which has a shorter main stem and leaves that initially expand horizontally. In an additional wind tunnel experiment, we examined the architectural influence on HIPV preference using single detached leaves from B. nigra and B. rapa instead of intact plants. The wasps used in this experiment had been reared from $P$. brassicae larvae on B. nigra. Leaves infested by 20 first-instar P. brassicae larvae for $24 \mathrm{~h}$ were cut and put into vials with water, and were allowed to recover for $2-4 \mathrm{~h}$ before they were used in a wind tunnel experiment. This comparison was tested in 10 replicate bioassays.

Furthermore, wasps can also be conditioned by exposure to HIPVs when they emerge from the host caterpillars prior to pupation and cocoon construction but in the presence of plant material [58]. As described above, one group of wasps was collected and separated from its host and the host plants prior to egression and cocoon construction, whereas another group of wasps was left with its host and host plants through egression and cocoon construction until adult eclosion. Landing preference $(n=10)$ was compared when wasps of these two groups were offered a host-infested S. arvensis and B. rapa plant, while the insects had been reared on S. arvensis. 


\subsection{Wind Tunnel Experiment}

Volatile-mediated foraging behaviour was studied in a wind tunnel set-up, which is described in detail in [59]. The environmental conditions were set as follows: wind speed, $0.1 \mathrm{~m} \cdot \mathrm{s}^{-1}$; light intensity 500-1000 Lux: temperature $25 \pm 1{ }^{\circ} \mathrm{C}$; relative humidity $60 \% \pm 5 \%$. To stimulate foraging of $C$. glomerata, females were exposed to a host-damaged Brussels sprout leaf from which the P. brassicae caterpillars had been removed. Female wasps were collected in $7-\mathrm{mL}$ glass vials and wasps were released individually in a "release cylinder" located in the middle of the wind tunnel. Two test plants were placed approximately $60-70 \mathrm{~cm}$ up-wind from the release cylinder.

Each wasp was observed for a maximum of $15 \mathrm{~min}$. When a wasp did not land on one of the two plants within $15 \mathrm{~min}$, it was recorded as "non-responding" and this data point was excluded from the statistical analysis. In each bioassay with one test plant combination, we tested 10 responding wasps, which served as a single data point. Each test plant combination in relation to the wasp's rearing history was tested 8-10 times with a new set of plants and each wasp was used only once. The response of a total of 1170 wasps was recorded in the bioassays examining the effect of rearing history, whereas 100 wasps were tested in each of the two additional bioassays.

\subsection{Volatile Collection and Analysis of Herbivore Infested Plants}

Volatiles emitted by B. rapa, S. arvensis, and B. nigra, which had been exposed to feeding by 20 first instar P. brassicae caterpillars for $24 \mathrm{~h}$ were collected and analysed. Plants were treated similarly as described for the behaviour bioassay. Volatiles were collected from individual plants, with 9-13 plants per species. The potting soil of the plants around the stem was wrapped in aluminium foil to reduce the release of plastic- and soil-related volatiles before the plants with the caterpillars remaining on them were transferred to a 30-L glass jar containers. Glass jars were sealed with viton-lined glass lids equipped with an air inlet and outlet. Pre-cleaned compressed air filtered through charcoal was led into the glass jars, and the plants were allowed to acclimatize for $40 \mathrm{~min}$. Dynamic headspace volatile collection was carried out in a laboratory at $20 \pm 2{ }^{\circ} \mathrm{C}$, by sucking air out of the jar at a rate of $200 \mathrm{~mL} \cdot \mathrm{min}^{-1}$ for $2 \mathrm{~h}$ through a stainless steel cartridge containing $200 \mathrm{mg}$ Tenax TA (20/35 mesh; CAMSCO, Houston, TX, USA). Immediately after volatile collection, foliar fresh weight of each plant was measured and the Tenax TA cartridges containing sample volatiles were dry-purged under a flow of nitrogen $\left(50 \mathrm{~mL} \cdot \mathrm{min}^{-1}\right)$ for $10 \mathrm{~min}$ at room temperature $\left(21 \pm 2{ }^{\circ} \mathrm{C}\right)$ to remove moisture and stored till analysis. Periodically, volatiles from just pots with soil wrapped in aluminium foil were collected and the compounds recorded, together with the volatiles originating from the Tenax TA adsorbent and the analytical instruments were excluded as artefacts from the data obtained for the plant samples as a correcting measure. Headspace volatile samples were analysed by using a Thermo Trace Ultra Gas Chromatography (GC) coupled to a Thermo Trace DSQ quadrupol mass spectrometer (MS) (both from Thermo (Thermo Fisher Scientific, Waltham, MA, USA) and were used for the separation and detection of volatile compounds. For details of the analytical protocol please refer to [60].

\subsection{Statistical Analysis}

To statistically analyse P. brassicae female butterfly oviposition preference, we used $\chi^{2}$-tests comparing the observed oviposition preference counts for the three plant species with an expected distribution of 1:1:1. When the test result was significant, we conducted pairwise $\chi^{2}$-square tests with $\alpha=0.05 / 3$ to correct for type I errors (Bonferroni correction).

The response variable in the statistical analyses of the C. glomerata wind tunnel bioassays is the fraction of wasps out of the total of 10 responding wasps choosing one of the plant species that was set to be the focal odour source. We used logistic regression, i.e., a generalized linear model (GLM) with binomial variable distribution for errors and a logit link function to determine the effect of rearing history on wasp landing preference for each plant pair combination. In the case of over-dispersion, we corrected for this by allowing the variance functions of the binomial distribution to 
have a multiplicative over-dispersion factor. Plant species on which the wasps were reared was entered as the explanatory variable in the regression model. To determine whether there was a significant preference for one of the odour sources within a plant pair, we tested $\mathrm{H}_{0}=\operatorname{logit}=0$ based on model term estimates of the GLM model. Additionally, we used one-sample $t$-tests to determine whether there was a preference for one of the two odour sources within a plant-pair comparison ignoring the effect of diet with $\mathrm{H}_{0}$ : no preference, mean preference fraction is 0.5 . We used a similar GLM approach for the data on the effect of plant architecture and the effect of early HIPV exposure on wasps landing preference, respectively.

We used one-way ANOVA to examine differences in leaf damage on the three host plants.

A multivariate statistical approach was used, i.e., principal component analysis (PCA), to visualize whether volatile profiles could be separated according to plant species and to determine which volatile compounds contributed the most to the separation. All volatiles compounds were included in the analysis. Univariate Kruskal-Wallis tests were employed to reveal significant differences in the emission of each volatile among the three plant species. We used ANOVA to analyse differences in total amounts of volatiles (log-transformed).

PCA analysis on all volatile data was performed in Canoco version 5.03 (ter Braak and Šmilauer, Microcomputer Power, Ithaca, NY, USA). All the other analyses were performed using SAS 9.3 (SAS Institute Inc., Cary, NC, USA).

\section{Conclusions}

We have shown that, in an insect herbivore and its gregarious endoparasitoid, innate, conditioned responses are unimportant in terms of food plant preference. This is adaptive because of life-history traits in the herbivore and its parasitoid: the food plants are all short-lived annuals with little temporal overlap in seasonal phenology and the insects are multivoltine, with up to three generations per year. Therefore, in nature, different generations of the insects are obligatorily associated with different plant species that may grow some distance apart.

Acknowledgments: The authors wish to thank Leon Westerd and Andre Gidding at Wageningen University for the insect cultures and Roel Wagenaar at Netherlands Institute of Ecology (NIOO) for rearing Cotesia glomerata. This study was supported by a grant from the China Scholarship Council. This is NIOO publication number 6138.

Author Contributions: Minghui Fei, Rieta Gols, Jeffrey A. Harvey and Louise M. Vet designed the experiments; Minghui Fei, Kimmy Reijngoudt, Tzeyi Huang and Rieta Gols conducted the experiments; Minghui Fei, Rieta Gols, Berhane T. Weldegergis and Tzeyi Huang collected samples and performed the chemical analyses; and Minghui Fei, Rieta Gols, Berhane T. Weldegergis and Jeffrey A. Harvey wrote the manuscript.

Conflicts of Interest: The authors declare no conflict of interest.

\section{References}

1. Meiners, T. Chemical ecology and evolution of plant-insect interactions: A multitrophic perspective. Curr. Opin. Insect Sci. 2015, 8, 22-28. [CrossRef]

2. Wäschke, N.; Hardge, K.; Hancock, C.; Hilker, M.; Obermaier, E.; Meiners, T. Habitats as complex odour environments: How does plant diversity affect herbivore and parasitoid orientation? PLOS ONE 2014, 9, e85152. [CrossRef] [PubMed]

3. Vet, L.E.M.; Wäckers, F.L.; Dicke, M. How to hunt for hiding hosts: The reliability-detectability problem in foraging parasitoids. Neth. J. Zool. 1990, 41, 202-213. [CrossRef]

4. Vinson, S.B.; Bin, F.; Vet, L.E.M. Critical issues in host selection by insect parasitoids. Biol. Cont. 1998, 11, 77-78. [CrossRef]

5. Schoonhoven, L.M.; van Loon, J.J.A.; Dicke, M. Insect-Plant Biology, 2nd ed.; Oxford University Press: Oxford, UK, 2005.

6. Traynier, R.M.M. Visual learning in assays of sinigrin solution as an oviposition releaser for the cabbage butterfly, Pieris rapae. Entomol. Exp. Appl. 1986, 40, 25-33. [CrossRef]

7. Vet, L.E.M.; Dicke, M. Ecology of infochemical use by natural enemies in a tritrophic context. Annu. Rev. Entomol. 1992, 37, 141-172. [CrossRef] 
8. De Boer, J.G.; Posthumus, M.A.; Dicke, M. Identification of volatiles that are used in discrimination between plants infested with prey or nonprey herbivores by a predatory mite. J. Chem. Ecol. 2004, 30, 2215-2230. [CrossRef] [PubMed]

9. Turlings, T.C.J.; Tumlinson, J.H.; Lewis, W.J. Exploitation of herbivore-induced plant odors by host-seeking parasitic wasps. Science 1990, 250, 1251-1253. [CrossRef] [PubMed]

10. Mumm, R.; Dicke, M. Variation in natural plant products and the attraction of bodyguards involved in indirect plant defense. Can. J. Zool. 2010, 88, 628-667. [CrossRef]

11. Arimura, G.; Matsui, K.; Takabayashi, J. Chemical and molecular ecology of herbivore-induced plant volatiles: Proximate factors and their ultimate functions. Plant Cell Physiol. 2009, 50, 911-923. [CrossRef] [PubMed]

12. Dicke, M.; Baldwin, I.T. The evolutionary context for herbivore-induced plant volatiles: Beyond the "cry for help". Trends Plant Sci. 2010, 15, 167-175. [CrossRef] [PubMed]

13. McCormick, A.C.; Unsicker, S.B.; Gershenzon, J. The specificity of herbivore-induced plant volatiles in attracting herbivore enemies. Trends Plant Sci. 2012, 17, 303-310. [CrossRef] [PubMed]

14. Loxdale, H.D.; Lushai, G.; Harvey, J.A. The evolutionary improbability of "generalism" in nature, with special reference to insects. Biol. J. Linn. Soc. 2011, 103, 1-18. [CrossRef]

15. Loxdake, H.D.; Harvey, J.A. The "generalism" debate: Misinterpreting the term in the empirical literature focusing on dietary breadth in insects. Biol. J. Linn. Soc. 2016. [CrossRef]

16. Fraenkel, G.S. The raison d'Être of secondary plant substances: These odd chemicals arose as a means of protecting plants from insects and now guide insects to food. Science 1959, 129, 1466-1470. [CrossRef] [PubMed]

17. Van Loon, J.J.A.; Blaakmeer, A.; Griepink, F.C.; van Beek, T.A.; Schoonhoven, L.M.; de Groot, A. Leaf surface compound from Brassica oleracea (Cruciferae) induces oviposition by Pieris brassicae (Lepidoptera: Pieridae). Chemoecology 1992, 3, 39-44. [CrossRef]

18. Cornell, H.V.; Hawkins, B.A. Herbivore responses to plant secondary compounds: A test of phytochemical coevolution theory. Am. Nat. 2003, 161, 507-522. [CrossRef] [PubMed]

19. Gols, R.; Harvey, J.A. Plant-mediated effects in the Brassicaceae on the performance and behaviour of parasitoids. Phytochem. Rev. 2009, 8, 187-206. [CrossRef]

20. Hopkins, R.J.; van Dam, N.M.; van Loon, J.J.A. Role of glucosinolates in insect-plant relationships and multitrophic interactions. Annu. Rev. Entomol. 2009, 54, 57-83. [CrossRef] [PubMed]

21. Renwick, J.A.A.; Radke, C.D.; Sachdev-Gupta, K.; Städler, E. Leaf surface chemicals stimulating oviposition by Pieris rapae (Lepidoptera: Pieridae) on cabbage. Chemoecology 1992, 3, 33-38. [CrossRef]

22. Vet, L.E.M.; de Jong, A.G.; Franchi, E.; Papaj, D.R. The effect of complete versus incomplete information on odour discrimination in a parasitic wasp. Anim. Behav. 1998, 55, 1271-1279. [CrossRef] [PubMed]

23. Papaj, D.R.; Prokopy, R.J. Ecological and evolutionary aspects of learning in phytophagous insects. Annu. Rev. Entomol. 1989, 34, 315-350. [CrossRef]

24. Emden, H.F.V.; Sponagl, B.; Wagner, E.; Baker, T.; Ganguly, S.; Douloumpaka, S. Hopkins' "host selection principle", another nail in its coffin. Physiol. Entomol. 1996, 21, 325-328. [CrossRef]

25. Barron, A. The life and death of Hopkins' host-selection principle. J. Insect Behav. 2001, 14, 725-737. [CrossRef]

26. Immelmann, K. Ecological significance of imprinting and early learning. Ann. Rev. Ecol. System. 1975, 6, 15-37. [CrossRef]

27. Davis, J.M.; Stamps, J.A. The effect of natal experience on habitat preferences. Trends Ecol. Evol. 2004, 19, 411-416. [CrossRef] [PubMed]

28. Davis, J.M. Patterns of variation in the influence of natal experience on habitat choice. Q. Rev. Biol. 2008, 83, 363-380. [CrossRef] [PubMed]

29. Gotthard, K.; Nylin, S. Adaptive plasticity and plasticity as an adaptation: A selective review of plasticity in animal morphology and life history. Oikos 1995, 74, 3-17. [CrossRef]

30. Gullan, P.J.; Cranston, P.S. The Insects: An Outline of Entomology, 4th ed.; Wiley-Blackwell: Oxford, UK, 2010.

31. Fei, M.; Gols, R.; Harvey, J.A. Seasonal phenology of interactions involving short-lived annual plants, a multivoltine herbivore and its endoparasitoid wasp. J. Anim. Ecol. 2014, 83, 234-244. [CrossRef] [PubMed]

32. Fei, M.; Gols, R.; Zhu, F.; Harvey, J.A. Plant quantity affects development and survival of a gregarious insect herbivore and its endoparasitoid wasp. PLoS ONE 2016, 11, e0149539. [CrossRef] [PubMed]

33. Liu, S.S.; Li, Y.H.; Liu, Y.Q.; Zalucki, M.P. Experience-induced preference for oviposition repellents derived from a non-host plant by a specialist herbivore. Ecol. Lett. 2005, 8, 722-729. [CrossRef] 
34. Anderson, P.; Anton, S. Experience-based modulation of behavioural responses to plant volatiles and other sensory cues in insect herbivores. Plant Cell Environ. 2014, 37, 1826-1835. [CrossRef] [PubMed]

35. Olsson, P.O.C.; Anderbrant, O.; Löfstedt, C. Experience influences oviposition behaviour in two pyralid moths, Ephestia cautella and Plodia interpunctella. Anim. Behav. 2006, 72, 545-551. [CrossRef]

36. Akhtar, Y.; Shikano, I.; Isman, M.B. Topical application of a plant extract to different life stages of Trichoplusia ni fails to influence feeding or oviposition behaviour. Entomol. Exp. Appl. 2009, 132, 275-282. [CrossRef]

37. Anderson, P.; Sadek, M.; Larsson, M.; Hansson, B.; Thöming, G. Larval host plant experience modulates both mate finding and oviposition choice in a moth. Anim. Behav. 2013, 85, 1169-1175. [CrossRef]

38. Moreau, J.; Rahme, J.; Benrey, B.; Thiéry, D. Larval host plant origin modifies the adult oviposition preference of the female European grapevine moth Lobesia botrana. Naturwissenschaften 2008, 95, 317-324. [CrossRef] [PubMed]

39. Armstrong, J.D.; de Belle, J.S.; Wang, Z.; Kaiser, K. Metamorphosis of the mushroom bodies; large-scale rearrangements of the neural substrates for associative learning and memory in Drosophila. Learn. Mem. 1998, 5, 102-114. [PubMed]

40. Ray, S. Survival of olfactory memory through metamorphosis in the fly Musca domestica. Neurosci. Lett. 1999, 259, 37-40. [CrossRef]

41. Feltwell, J. Large White Butterfly: The Biology, Biochemistry and Physiology of Pieris Brassicae (Linnaeus); Springer: Berlin, Germany, 1982.

42. Le Masurier, A.D. Costs and benefits of egg clustering in Pieris brassicae. J. Anim. Ecol. 1994, 63, 677-685. [CrossRef]

43. Morris, R.; Fellowes, M. Learning and natal host influence host preference, handling time and sex allocation behaviour in a pupal parasitoid. Behav. Ecol. Sociobiol. 2002, 51, 386-393.

44. Hérard, F.; Keller, M.; Lewis, W.J.; Tumlinson, J. Beneficial arthropod behavior mediated by airborne semiochemicals. J. Chem. Ecol. 1988, 14, 1583-1596. [CrossRef] [PubMed]

45. Gols, R.; Veenemans, C.; Potting, R.P.J.; Smid, H.M.; Dicke, M.; Harvey, J.A.; Bukovinszky, T. Variation in the specificity of plant volatiles and their use by a specialist and a generalist parasitoid. Anim. Behav. 2012, 83, 1231-1242. [CrossRef]

46. Gandolfi, M.; Mattiacci, L.; Dorn, S. Preimaginal learning determines adult response to chemical stimuli in a parasitic wasp. Proc. R. Soc. B: Biol. Sci. 2002, 270, 2623-2629. [CrossRef] [PubMed]

47. Rossbach, A.; Löhr, B.; Vidal, S. Does a specialist parasitoid adapt to its host on a new host plant? J. Insect Behav. 2006, 19, 479-495. [CrossRef]

48. Bjorksten, T.; Hoffmann, A. Separating the effects of experience, size, egg load, and genotype on host response in Trichogramma (Hymenoptera: Trichogrammatidae). J. Insect Behav. 1998, 11, 129-148. [CrossRef]

49. Bradburne, R.P.; Mithen, R. Glucosinolate genetics and the attraction of the aphid parasitoid Diaeretiella rapae to Brassica. Proc. R. Soc. B: Biol. Sci. 2000, 267, 89-95. [CrossRef] [PubMed]

50. Blande, J.; Pickett, J.; Poppy, G. A comparison of semiochemically mediated interactions involving specialist and generalist Brassica-feeding aphids and the braconid parasitoid Diaeretiella rapae. J. Chem. Ecol. 2007, 33, 767-779. [CrossRef] [PubMed]

51. Geervliet, J.B.; Vreugdenhil, A.I.; Dicke, M.; Vet, L.E.M. Learning to discriminate between infochemicals from different plant-host complexes by the parasitoids Cotesia glomerata and C. rubecula. Entomol. Exp. Appl. 1998, 86, 241-252. [CrossRef]

52. Gols, R.; van Dam, N.M.; Raaijmakers, C.E.; Dicke, M.; Harvey, J.A. Are population differences in plant quality reflected in the preference and performance of two endoparasitoid wasps? Oikos 2009, 118, 733-742. [CrossRef]

53. Bukovinszky, T.; Gols, R.; Posthumus, M.; Vet, L.E.M.; van Lenteren, J.C. Variation in plant volatiles and attraction of the parasitoid Diadegma semiclausum (Hellen). J. Chem. Ecol. 2005, 31, 461-480. [CrossRef] [PubMed]

54. Fahey, J.W.; Zalcmann, A.T.; Talalay, P. The chemical diversity and distribution of glucosinolates and isothiocyanates among plants. Phytochemistry 2001, 56, 5-51. [CrossRef]

55. Halkier, B.A.; Gershenzon, J. Biology and biochemistry of glucosinolates. Annu. Rev. Plant Biol. 2006, 57, 303-333. [CrossRef] [PubMed] 
56. Gols, R.; Bullock, J.M.; Dicke, M.; Bukovinszky, T.; Harvey, J.A. Smelling the wood from the trees: Non-linear parasitoid responses to volatile attractants produced by wild and cultivated cabbage. J. Chem. Ecol. 2011, 37, 795-807. [CrossRef] [PubMed]

57. Read, D.P.; Feeny, P.P.; Root, R.B. Habitat selection by the aphid parasite Diaeretiella rapae (Hymenoptera: Braconidae) and hyperparasite Charips brassicae (Hymenoptera: Cynipidae). Can. Entomol. 1970, 102, 1567-1578. [CrossRef]

58. Kester, K.; Barbosa, P. Postemergence learning in the insect parasitoid, Cotesia congregata (Say)(Hymenoptera: Braconidae). J. Insect Behav. 1991, 4, 727-742. [CrossRef]

59. Geervliet, J.B.; Vet, L.E.M.; Dicke, M. Volatiles from damaged plants as major cues in long-range host-searching by the specialist parasitoid Cotesia rubecula. Entomol. Exp. Appl. 1994, 73, 289-297. [CrossRef]

60. Cusumano, A.; Weldegergis, B.T.; Colazza, S.; Dicke, M.; Fatouros, N. Attraction of egg-killing parasitoids toward induced plant volatiles in a multi-herbivore context. Oecologia 2015, 179, 163-174. [CrossRef] [PubMed]

(C) 2016 by the authors; licensee MDPI, Basel, Switzerland. This article is an open access article distributed under the terms and conditions of the Creative Commons Attribution (CC-BY) license (http://creativecommons.org/licenses/by/4.0/). 